\title{
The comparing of infant mortality rate in different World Health Organization regions during 1990-2017
}

\author{
Firooz Esmaeilzadeh ${ }^{1}$, Yousef Alimohamadi ${ }^{2,3^{*}}$, Mojtaba Sepandi ${ }^{4,5}$, Farzad Khodamoradi ${ }^{6}$ and Parisa Jalali ${ }^{3}$
}

\begin{abstract}
Background: Infant mortality rate is an important index of community health status and mortality rate. It is also one of the most prominent indexes showing the development of various societies. Regarding the importance of infant mortality rate (IMR), the purpose of current study was to compare and trend analysis of IMR in different areas of the WHO during 1990-2017. In current ecological study, IMR per 1000 live births in different WHO regions from 1990 to 2017 data were derived from the WHO website. The required information included the data about IMR per 1000 live births in different WHO regions from 1990 to 2017. The analysis was performed by using descriptive and analytical methods.

Results: The IMR during the study period had a significant decreasing trend in all the regions $(p<0.001)$ but the slope of decrease was greater in Africa than in other regions. The African and European regions had the highest (55.7\%) and lowest (17.2\%) annual decrease in the infant mortality rate (from 106.3 cases in 1990 to 50.6 in 2017, and from 24.9 in 1990 to 7.7 in 2017), respectively.
\end{abstract}

Conclusion: Our results showed that the trend of IMR had a decreasing trend in all WHO regions. It can be due to improving the public health situation in different areas. But the identification of effective factors on IMR needs individuals based studies.

Keywords: Infant mortality, WHO regions, Public health, Health equity, Global health

\section{Background}

Awareness about the mortality in population and its common causes have an effective role in health planning and education [1]. Maintaining and promoting the health of infants younger than 1 year of age as a vulnerable group in health services is of special importance [2]. Infant mortality rate (IMR) is an important index of community health status and mortality rate and is also one of the most prominent indexes showing the development of various societies [3]. It is an accepted global

\footnotetext{
*Correspondence: y.alimohamadi67@gmail.com

${ }^{2}$ Antimicrobial Resistance Research Center, Institute of Immunology and Infectious Diseases, Iran University of Medical Sciences, Tehran, Iran ${ }^{3}$ Department of Epidemiology and Biostatistics, School of Public Health, Tehran University of Medical Sciences, Tehran, Iran

Full list of author information is available at the end of the article
}

index of health and socioeconomic status of a certain population [3]. This statistical indicator not only shows the quantity and number of deaths but also is expressive of life quality [3]. While neonatal health is dependent on health care services, post-neonatal health is more dependent on environmental factors $[4,5]$. Increasing IMR can be attributed to dissatisfied hygienic requirements, undesirable environmental factors, economic conditions, environmental health, and health care [6]. The results of studies have shown that the highest rate of infant mortality occurred during the neonatal period, especially during the first week [3]. The most important causes of neonatal mortality are low birth weight and prematurity, and the major causes of death during the post-neonatal period are diarrhea and respiratory infections as well [3, 6-11]. According to recent estimates, 
about 120-156 million cases of acute respiratory infections, especially pneumonia and bronchitis, occur every year with approximately 1.4 million deaths. More than $95 \%$ of these deaths occur in low- and middle-income countries [12]. Other factors such as socioeconomic class, malnutrition, mother's age, breastfeeding, the interval from the previous delivery, delivery place, and type of delivery can also contribute to infant mortality $[3,13]$. Given that the mortality rate of the infants under 1 year is one of the important health indicators and different countries have been working hard to improve the quality of life and reduce infant mortality in recent decades, this study aimed to compare and trend analysis of infant mortality rate (mortality before the age of 1 year) in different areas of the World Health Organization during 1990-2017.

\section{Methods}

In the present ecological study, the needed information was obtained from the WHO website with the following address: http://apps.who.int/gho/data/view.main.CM13 00R?lang=en. The information included the data about the infant or under-1-year-old children's mortality rates per 1000 live births in different WHO regions in different years from 1990 to 2017. The WHO has six regions including Africa, the Americas, Southeast Asia, Europe, Eastern Mediterranean, and Western Pacific. We extracted and analyzed the information of all the regions. The descriptive statistical methods such as mean and standard deviation as well as the analytical statistics like one-way ANOVA and post hoc Scheffé tests were used for comparing the mean infant mortality rates in different regions. Also, the Pearson correlation coefficient to assess the changing trend of infant mortality rate over time was used. All the analyses were performed using Excel 2010 and SPSS 22 with regard to the significance level of $\alpha: 0.05$.

\section{Results}

The infant mortality rate during the study period had a decreasing trend in all the regions but the slope of decrease was greater in Africa than in other regions. After Africa, the slope of decrease was greater in Southeast Asia and the Eastern Mediterranean. The beginning severe change in the Africa region was regarding 2000 to 2010 , before and after this period slope was slow. In Southeast Asia in all the periods of the study, sharp slope was but humdrum and changes the process was similar in the other regions (Fig. 1). The decreasing trend over time in all the regions was statistically significant $(p<0.001)$ (Table 1). Over the years of study, the African and European regions had the highest (55.7\%) and lowest (17.2\%) annual decrease in the infant mortality rate (from 106.3 cases in 1990 to 50.6 in 2017, and from 24.9 in 1990 to 7.7 in 2017), respectively (Fig. 2). Also, as shown in Table 2, the highest and lowest rates of IMR during the mentioned period were observed in Africa (80.87 per 1000) and Europe (15.63 per 1000), respectively. There was also a statistically significant difference between different regions in terms of the total IMR mean in the study period $(p<0.001)$. But the observed difference between the IMR means of America

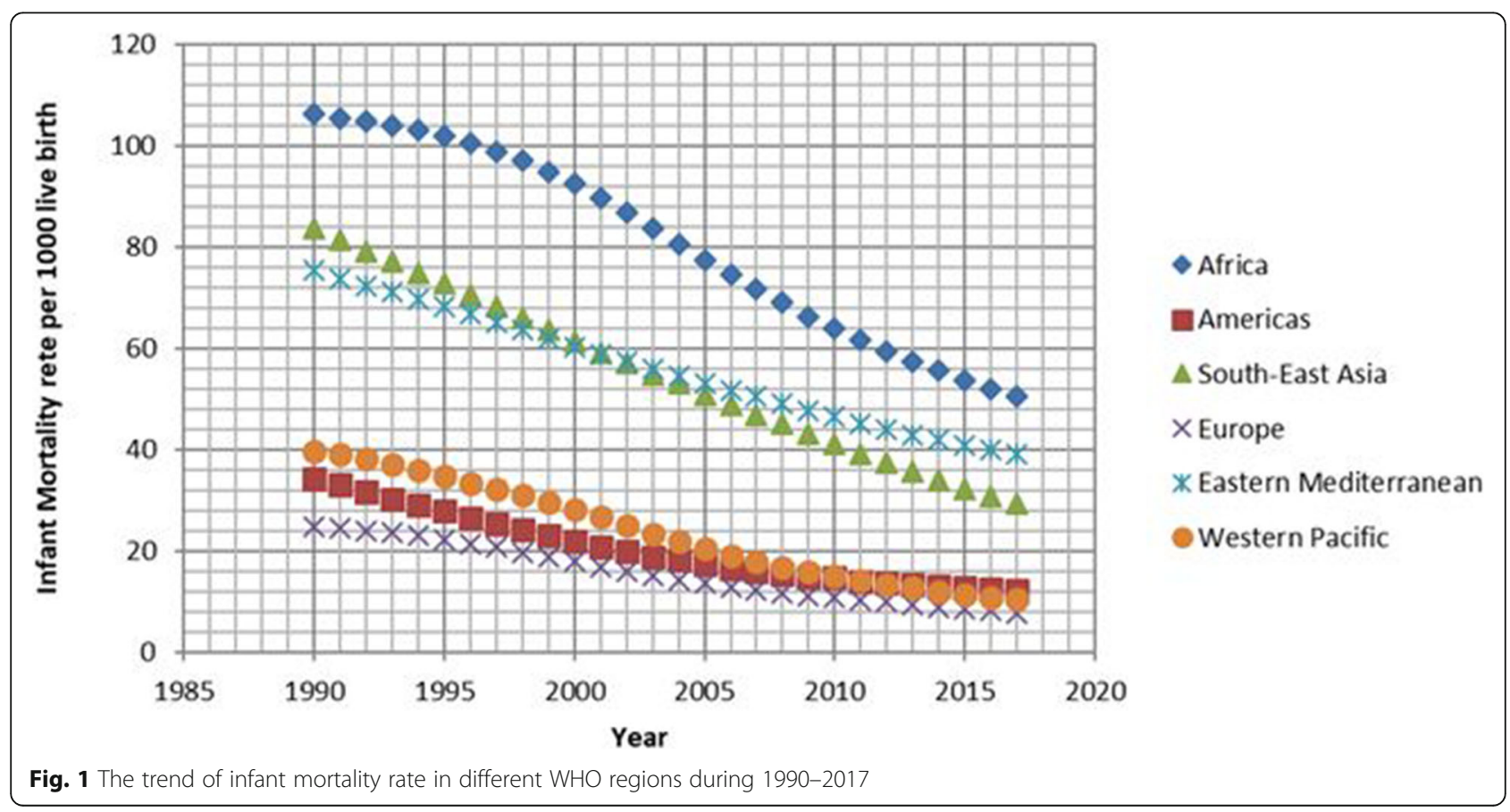


Table 1 The trend analysis of infant mortality rate in different WHO regions during 1990-2017

\begin{tabular}{|c|c|c|c|c|c|c|c|}
\hline \multicolumn{2}{|c|}{ Time-IMR } & \multirow{2}{*}{$\begin{array}{l}\text { Africa } \\
-.99^{\mathrm{a}}\end{array}$} & \multirow{2}{*}{$\begin{array}{l}\text { Americas } \\
-.97^{a}\end{array}$} & \multirow{2}{*}{$\begin{array}{l}\text { Southeast Asia } \\
-.99^{\mathrm{a}}\end{array}$} & \multirow{2}{*}{$\begin{array}{l}\text { Europe } \\
-.99^{\mathrm{a}}\end{array}$} & \multirow{2}{*}{$\begin{array}{l}\text { Eastern Mediterranean } \\
-.99^{\mathrm{a}}\end{array}$} & \multirow{2}{*}{$\frac{\text { Western Pacific }}{-.99^{\mathrm{a}}}$} \\
\hline Time & Pearson correlation $(r)$ & & & & & & \\
\hline & $P$ & $<0.001$ & $<0.001$ & $<0.001$ & $<0.001$ & $<0.001$ & $<0.001$ \\
\hline & $N$ & 28 & 28 & 28 & 28 & 28 & 28 \\
\hline
\end{tabular}

${ }^{a}$ Correlation is significant at the 0.01 level (2-tailed)

and Europe and that of the Western Pacific was not significant $(p>0.05)$ (Table 3). Considering the year 1990 as the base year, the highest and lowest marginal effectiveness of all the measures taken to reduce mortality in 2012 were found in Southeast Asia (a reduction of 2.3 deaths per 100,000 live births compared to the previous year) and Europe (a reduction of 0.5 deaths per 100,000 live births compared to the previous year), respectively, and the trend continued until 1999. During 1991-1999, the marginal effectiveness of the measures taken to reduce mortality in Africa, Europe, and the Western Pacific had almost a rising trend, but this increase was greater in the Western Pacific and especially in Africa, so that after 1999 the marginal effectiveness of the measures taken in Africa was more than the other regions, and the infant mortality rate declined with a falling trend until 2003. Since 2005, there has been a declining trend in almost all countries (Fig. 2). The mean of vaccination coverage of diphtheria tetanus toxoid and pertussis (DTP3), measles, 2nd dose (MCV2), polio (Pol3), pneumococcal conjugate (PCV3), and hepatitis B (HepB3) during the last decades in who region was showed in Table 4. It seems the mean of vaccination coverage for the mentioned vaccine for the Americas, Europe, and West Pacific is better than other regions.

\section{Discussion}

During the study years, the infant mortality rate declined in all regions of the World Health Organization; one of the main reasons for this decrease could be the perinatal mortality rate. According to the results of Ebrahimvandi's study [14], reduced PMR by 0.9 deaths per 1000 people could reduce IMR by $56 \%$ in some regions, and PMR reduction was itself affected by increased prenatal care. The trend of IMR is declining in all areas, but there is a long way to go, as in some countries preventable deaths account for more than three quarters of infant deaths, with more than half of these deaths being prevented by caring for women during pregnancy and around childbirth [15]. The pattern of infant mortality has varied with interventions conducted in developed countries. Developed areas have reduced the impact of

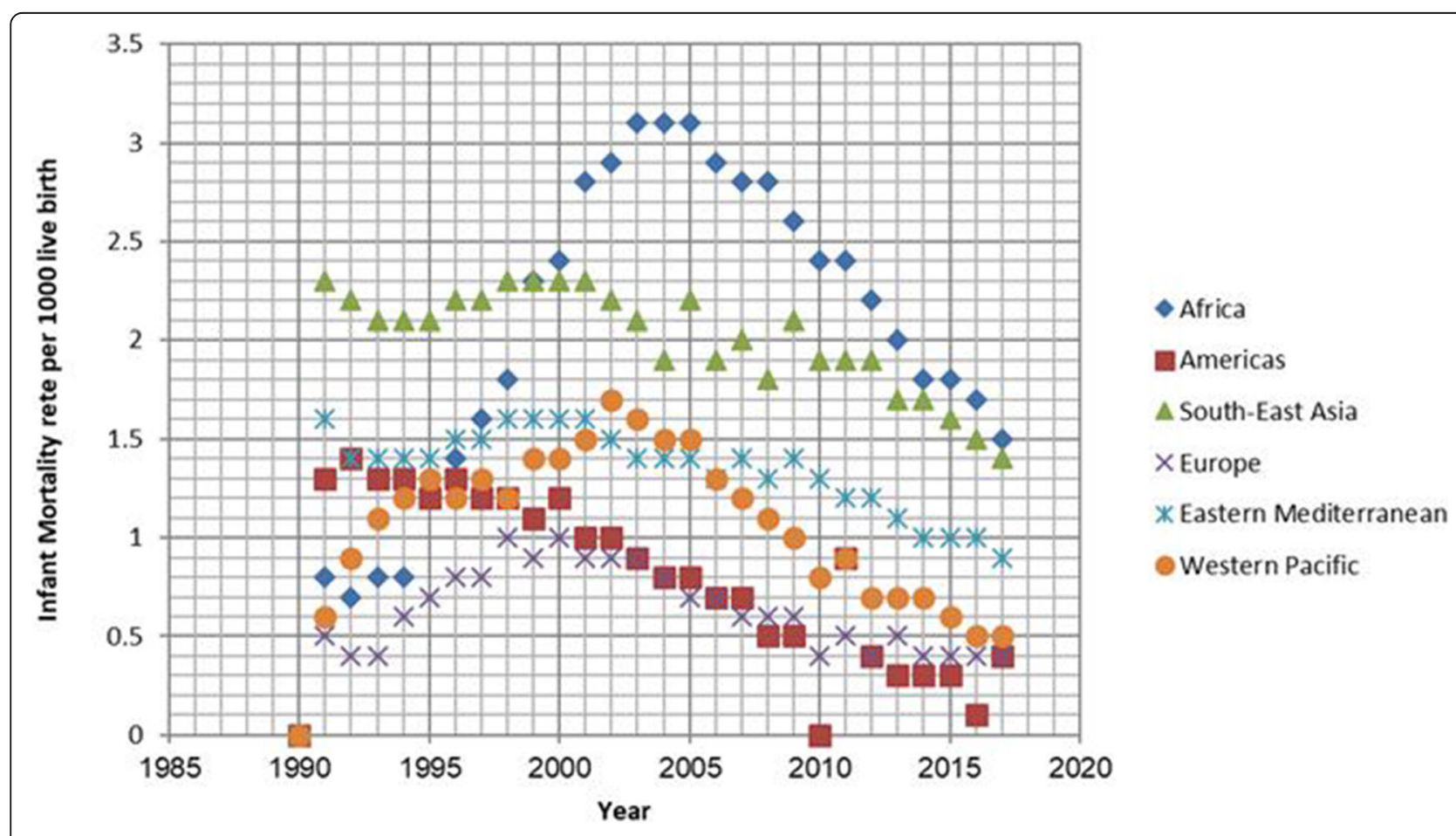

Fig. 2 The marginal effectiveness of all measures influencing infant mortality rate in the six regions of the World Health Organization from 1990 to 2017 
Table 2 The result of the comparison infant mortality rate in different WHO regions during 1990-2017

\begin{tabular}{|c|c|c|c|c|c|c|c|c|}
\hline \multirow[t]{2}{*}{ WHO region } & \multirow[t]{2}{*}{$N$} & \multirow[t]{2}{*}{ Mean } & \multirow{2}{*}{$\begin{array}{l}\text { Std. } \\
\text { deviation }\end{array}$} & \multicolumn{2}{|c|}{$95 \%$ confidence interval for mean } & \multirow[t]{2}{*}{ Minimum } & \multirow[t]{2}{*}{ Maximum } & \multirow[t]{2}{*}{$P$} \\
\hline & & & & Lower bound & Upper bound & & & \\
\hline Africa & 28 & 80.87 & 19.25 & 73.41 & 88.34 & 50.60 & 106.30 & $<0.001$ \\
\hline Americas & 28 & 20.38 & 6.95 & 17.68 & 23.07 & 12.20 & 34.30 & \\
\hline Southeast Asia & 28 & 54.91 & 16.86 & 48.37 & 61.44 & 29.40 & 83.60 & \\
\hline Europe & 28 & 15.63 & 5.75 & 13.40 & 17.86 & 7.70 & 24.90 & \\
\hline Eastern Mediterranean & 28 & 55.96 & 11.41 & 51.54 & 60.39 & 39.00 & 75.40 & \\
\hline Western Pacific & 28 & 23.80 & 9.92 & 19.96 & 27.65 & 10.40 & 39.80 & \\
\hline Total & 168 & 41.93 & 26.84 & 37.84 & 46.01 & 7.70 & 106.30 & \\
\hline
\end{tabular}

preventable factors on infant mortality by providing appropriate health services and essential education. Due to the increasing number of registered deaths and improved diagnoses of abnormalities that lead to termination of pregnancy, live births will occur in newborns who are severely underweight, which accounts for most of the deaths of an infant less than 1 year. For this reason, the main cause of death in these regions is congenital defects and chromosomal abnormalities [16]. IMR in different areas may have completely different causes, depending on the number of deaths under 1 year of age, specific interventions are needed to control them, in areas where deaths occur within 0 to 27 days causes are mostly related to pregnancy, childbirth care, and genetic abnormalities, whereas deaths over 28 days are mainly related to environmental factors and maternal literacy level [16]. In general, premature births, which are affected by congenital malformations and chromosomal abnormalities, are among the main causes of IMR in underdeveloped and developing areas [17-19]. Of course, sudden death syndrome and unintentional injuries in low economic and cultural status societies have a large impact on this rate [18]. Social factors, such as racial inequalities in employment, and educational services [20], childhood marriage, sexual injustice, cultural mutation, and religion cause psychological problems, are directly related to IMR. Therefore, screening, diagnosis, and home-based services can sometimes be the primary strategy to reduce IMR in each region [21]. In other studies, marriage status, gender, birth weight, and multiple births have been identified as predictors of IMR. Also, infants born from unmarried women, double or multiple births, and boys with a birth weight of fewer than $2500 \mathrm{~g}$, had a higher mortality rate $[17,22]$. The factors listed above may overlap with each other.

The reason for this decrease in mortality can be attributed to the greater sensitivity of health care providers as

Table 3 The result of Scheffé post hoc test in comparison to the infant mortality rate in different WHO regions during 1990-2017

\begin{tabular}{|c|c|c|c|c|c|c|}
\hline \multirow[t]{2}{*}{ (I) WHO region } & \multirow[t]{2}{*}{ (J) WHO region } & \multirow{2}{*}{$\begin{array}{l}\text { Mean } \\
\text { difference } \\
(I-J)\end{array}$} & \multirow{2}{*}{$\begin{array}{l}\text { Std. } \\
\text { error }\end{array}$} & \multirow[t]{2}{*}{$P$} & \multicolumn{2}{|c|}{ 95\% confidence interval } \\
\hline & & & & & Lower bound & Upper bound \\
\hline \multirow[t]{5}{*}{ Africa } & Americas & $60.49^{a}$ & 3.38 & $<0.001$ & 49.07 & 71.91 \\
\hline & Southeast Asia & $25.96^{\mathrm{a}}$ & 3.38 & $<0.001$ & 14.54 & 37.38 \\
\hline & Europe & $65.24^{\mathrm{a}}$ & 3.38 & $<0.001$ & 53.82 & 76.66 \\
\hline & Eastern Mediterranean & $24.91^{a}$ & 3.38 & $<0.001$ & 13.49 & 36.33 \\
\hline & Western Pacific & $57.07^{\mathrm{a}}$ & 3.38 & $<0.001$ & 45.65 & 68.49 \\
\hline \multirow[t]{4}{*}{ Americas } & Southeast Asia & $-34.52^{\mathrm{a}}$ & 3.38 & $<0.001$ & -45.94 & -23.10 \\
\hline & Europe & 4.74 & 3.38 & $<0.001$ & -6.67 & 16.16 \\
\hline & Eastern Mediterranean & $-35.58^{a}$ & 3.38 & $<0.001$ & -47.00 & -24.16 \\
\hline & Western Pacific & -3.42 & 3.38 & .960 & -14.84 & 7.99 \\
\hline \multirow[t]{3}{*}{ Southeast Asia } & Europe & $39.27^{\mathrm{a}}$ & 3.38 & $<0.001$ & 27.85 & 50.69 \\
\hline & Eastern Mediterranean & -1.05 & 3.38 & 1.000 & -12.47 & 10.36 \\
\hline & Western Pacific & $31.10^{\mathrm{a}}$ & 3.38 & $<0.001$ & 19.68 & 42.52 \\
\hline \multirow[t]{2}{*}{ Europe } & Eastern Mediterranean & $-40.33^{a}$ & 3.38 & $<0.001$ & -51.75 & -28.91 \\
\hline & Western Pacific & -8.17 & 3.38 & .330 & -19.59 & 3.24 \\
\hline Eastern Mediterranean & Western Pacific & $32.16^{a}$ & 3.38 & $<0.001$ & 20.74 & 43.58 \\
\hline
\end{tabular}

${ }^{\mathrm{a}}$ The mean difference is significant at the 0.05 level 
Table 4 The percentage of vaccination coverage in different WHO region during the last decade

\begin{tabular}{|c|c|c|}
\hline WHO regions & Vaccine type & $\begin{array}{l}\text { Mean of Immunization } \\
\text { coverage (\%) }\end{array}$ \\
\hline \multirow[t]{5}{*}{ Africa } & DTP3 & 52.82 \\
\hline & MCV2 & 8.95 \\
\hline & POLIO3 & 53.97 \\
\hline & PCV3 & 44.11 \\
\hline & НерВ3 & 45.52 \\
\hline \multirow[t]{5}{*}{ Americas } & DTP3 & 82.28 \\
\hline & MCV2 & 68.79 \\
\hline & POLIO3 & 83.67 \\
\hline & PCV3 & 68.36 \\
\hline & НерВ3 & 69.46 \\
\hline \multirow[t]{5}{*}{ Eastern Mediterranean } & DTP3 & 64.90 \\
\hline & MCV2 & 50.42 \\
\hline & POLIO3 & 65.82 \\
\hline & PCV3 & 31.70 \\
\hline & НерВ3 & 51.97 \\
\hline \multirow[t]{5}{*}{ Europe } & DTP3 & 87.38 \\
\hline & MCV2 & 78.21 \\
\hline & POLIO3 & 89.44 \\
\hline & PCV3 & 46.00 \\
\hline & НерВ3 & 55.32 \\
\hline \multirow[t]{5}{*}{ Southeast Asia } & DTP3 & 60.54 \\
\hline & MCV2 & 30.95 \\
\hline & POLIO3 & 59.67 \\
\hline & PCV3 & 10.50 \\
\hline & НерВ3 & 37.26 \\
\hline \multirow[t]{5}{*}{ Western Pacific } & DTP3 & 81.23 \\
\hline & MCV2 & 63.26 \\
\hline & POLIO3 & 84.08 \\
\hline & PCV3 & 7.18 \\
\hline & НерВ3 & 53.73 \\
\hline
\end{tabular}

the only intervention [23] Another study specifically examining the impact of these cares shows that women who received care from their first month of pregnancy only had one in fifteen infant mortalities in comparison to women who received no care during their pregnancy. Receiving care is affected by women's awareness and age; the lower the age of the pregnant woman, the less likely she is to seek and receive pregnancy care. Therefore, the youngest women are the highest risk group [17, 22].

Environmental factors such as smoking are effective factors on the incidence of diseases, so infant mortality is higher among smoker mothers. Maternal smoking increases the risk of respiratory infections and impedes the immune response of the infant [17]. Besides, smoking cessation by pregnant women, vaccination, reduced preterm deliveries, increased age of childbirth, economic growth in countries, and an increase in the health sector's share of the countries' income were known as other IMR reduction factors $[14,24,25]$. In a similar study conducted in European countries, a slower downward trend is occurring than in the past, but there are fluctuations in the different countries that may be influenced by birth cohort effect or period effect [17].

Successful countries in rapid control of the IMR have cited rapid economic progress as a reason for their success. In addition to reducing IMR, interventions in different areas change the pattern of mortality, which requires continuous monitoring and modifications of interventions to the desired level. Different effective factors can affect the IMR; these factors include the development of public health programs such as vaccination programs, Human Development Index (HDI), level of women empowerment, income inequality, GDP per capita, social inequalities, socioeconomic status, social economic and environmental hygiene. So a decreased trend of IMR in different areas may be because of improvement of the mentioned index such as development of vaccination programs, improvement of the nutritional status, increase in women educational level and women empowerment, and improvement of the human development index and GDP per capita [26, 27].

Despite the reduction in IMR in all regions, the IMR reduction rates varied significantly in different regions of the World Health Organization. Reducing mortality from infectious diseases is easier and faster than reducing the deaths due to congenital disorders, childhood cancers, and complications of preterm childbirth. So a higher percentage of deaths in Africa and Southeast Asia had occurred due to infectious diseases compared to regions such as Europe [28-30].

Also, the mentioned variation in IMR may be due to differences in some indicators such as vaccination coverage, HDI, level of women empowerment, income inequality, GDP per capita, social inequalities, socioeconomic status, and environmental hygiene. There is an inverse association between IMR and HDI; in other words, a region with a higher HDI index has a lower IMR. A similar association exists between IMR and the level of women empowerment, income inequality, and GDP per capita; social inequalities are other effective factors. Lower income and social inequality can decrease the level of IMR. So the lower amount of IMR in the Americas and Europe region can be because of a better HDI index, an increase in the number of educated women, lower income, and social inequality in mentioned areas [27].

In considering other effective factors on the difference of IMR between different WHO areas, ethnical factors can be regarded. Evaluation of the effect of maternal age 
on IMR showed that children born of mothers under 20 years had the highest and children born of mothers between 30 and 34 years had the lowest IMR [16]. In regions such as Europe where effective measures to reduce IMR had been started earlier, the marginal effectiveness of many effective measures to reduce IMR in those regions had declined in 1990 (the first year of the study). Hence, IMR would decrease in those regions with a decreasing rate. (Any action taken in different parts of the world to reduce IMR might have an increasing marginal effectiveness trend in the first stage so that in the first years, the number of reduced deaths as a result of that action in a specific population would increase each year compared to the previous one. After several years, the marginal effectiveness of the carried out action would reach the highest and then become decreasing.) But in regions such as Africa where the IMR-mitigating measures had started at a later stage, there was an increased efficiency of the actions at the beginning of the study. In other words, the IMR rate was increasingly reduced during 1990-2003, and the number of deaths in each year was lower than in the previous one. Since 2005, the marginal effectiveness of the measures taken in Africa has been declining, too, but the IMR is still numerically higher than in other regions.

Studies have shown that infant deaths in rural areas are significantly higher than in urban areas. And with the same interventions, the intensity reduction of deaths in rural areas is higher than in urban areas. Mortality due to congenital malformations in rural areas 20\% higher than in urban areas $[31,32]$. The quality of care provided is directly related to the development of the area, and this is due to the difference in infant mortality rates in villages relative to developed cities or countries compared to developing or less developed ones. The most direct cause of this discrepancy can be found in perinatal care (respiratory system diseases are the most important) followed by timely diagnosed malformations [31]. Given the decline in the IMR reduction rate in all the regions, maintaining this reduction in future years requires more investment in this area, so that, in addition to carrying out the current measures, countries must invest in programs such as improving maternal health behaviors (smoking, using alcohol and drugs during pregnancy) to control chronic diseases in mothers and increasing maternal education. It is the economic and social development of countries that can be a precondition for taking such measures [12, 33, 34].

\section{Conclusion}

The trend of IMR in different regions of WHO had a decreasing trend during the last decades but the amount of decrease is not the same in different areas. This is an ecological study so it is recommended to assess the effective factors on IMR among different regions by the individual-based studies. The comparison we made in this study with regard to the variance that exists at different regional levels can help in further investigations to discover and apply effective interventions that are successful at the regional level. Multilevel interventions may improve the health status of women, children, and their communities [35].

\section{Abbreviations}

IMR: Infant mortality rate; WHO: World Health Organization

\section{Acknowledgements}

We would also like to declare that I did not receive any funding for the preparation of this article.

\section{Authors' contributions}

$\mathrm{FE}$ and $\mathrm{Y} A$ contributed to the conception, design of the work, analysis and interpretation of data, and draft preparation and approved the submitted version. M S, F Kh, and P J designed of the work and contributed to the analysis and interpretation of data and draft preparation and edition. All authors read and approved the final manuscript.

Funding

This research did not receive any funding source.

Availability of data and materials

All data are available in $\mathrm{WHO}$ website.

Ethics approval and consent to participate

Not applicable. All data are available in WHO website.

Consent for publication

Not applicable

Competing interests

There is no conflict of interest.

\section{Author details}

${ }^{1}$ Department of Public Health, School of Public Health, Maragheh University of Medical Sciences, Maragheh, Iran. ${ }^{2}$ Antimicrobial Resistance Research Center, Institute of Immunology and Infectious Diseases, Iran University of Medical Sciences, Tehran, Iran. ${ }^{3}$ Department of Epidemiology and Biostatistics, School of Public Health, Tehran University of Medical Sciences, Tehran, Iran. ${ }^{4}$ Health Research Center, Life Style Institute, Baqiyatallah University of Medical Sciences, Tehran, Iran. ${ }^{5}$ Department of Epidemiology and Biostatistics, Faculty of Health, Baqiyatallah University of Medical Sciences, Tehran, Iran. ${ }^{6}$ Department of Community Medicine, School of Medicine, Dezful University of Medical Sciences, Dezful, Iran.

Received: 8 January 2020 Accepted: 9 December 2020

Published online: 11 January 2021

\section{References}

1. Rahbar M, Ahmadi M, Lornejad H, Habibelahi A, Sanaei-Shoar T, Mesdeaghinia A (2013) Mortality causes in children 1-59 months in Iran. Iran J P Health 42(Supple1):93

2. Kliegman RM, Behrman RE, Jenson HB, Stanton BM (2007) Nelson textbook of pediatrics e-book: Elsevier Health Sciences

3. Sharifzadeh GR, Namakin K, Mehrjoofard H (2008) An epidemiological study on infant mortality and factors affecting it in rural areas of Birjand, Iran. Iran J Pediatr 18(4):335-342

4. Mausner JS, Bahn AK (1974) Epidemiology. An introductory text

5. Park JE (1970) Textbook of preventive and social medicine (a treatise on community health)

6. Lawoyin T (2001) Risk factors for infant mortality in a rural community in Nigeria. J Royal Soc Promot Health 121(2):114-118 
7. Leach A, McArdle T, Banya W, Krubally O, Greenwood A, Rands C et al (1999) Neonatal mortality in a rural area of The Gambia. Ann Trop Paediatr 19(1):33-43

8. Yassin KM (2000) Indices and sociodemographic determinants of childhood mortality in rural Upper Egypt. Soc Sci Med 51(2):185-197

9. Suwal JV (2001) The main determinants of infant mortality in Nepal. Soc Sci Med 53(12):1667-1681

10. Agha S (2000) The determinants of infant mortality in Pakistan. Soc Sci Med 51(2):199-208

11. Al-Nahedh N (1997) Infant mortality in the rural Riyadh region of Saudi Arabia. J Royal Soc Promot Health 117(2):106-109

12. Sonego M, Pellegrin MC, Becker G, Lazzerini M (2015) Risk factors for mortality from acute lower respiratory infections (ALRI) in children under five years of age in low and middle-income countries: a systematic review and meta-analysis of observational studies. PloS one 10(1):e0116380

13. Munthali T, Jacobs C, Sitali L, Dambe R, Michelo C (2015) Mortality and morbidity patterns in under-five children with severe acute malnutrition (SAM) in Zambia: a five-year retrospective review of hospital-based records (2009-2013). Arch Pub Health 73(1):23

14. Ebrahimvandi A, Hosseinichimeh N, lams J (2019) Understanding state level variations in US infant mortality: 2000 to 2015. Am J Perinatol 36:1271-1277 arXiv preprint arXiv:180602475. 2018.

15. Areco KCN, Konstantyner T, Taddei JA (2016) Secular trends in infant mortality by age-group and avoidable components in the State of São Paulo, 1996-2012. Rev Paul Pediatr 34(3):263-270

16. Gava C, Cardoso AM, Basta PC (2017) Infant mortality by color or race from Rondônia, Brazilian Amazon. Rev Saude Publica 51:35

17. Mathews T, MacDorman MF (2013) Infant mortality statistics from the 2010 period linked birth/infant death data set. Natl Vital Stat Rep 62(8):1-26

18. MacDorman MF, Mathews T, Mohangoo AD, Zeitlin J (2014) International comparisons of infant mortality and related factors: United States and Europe, 2010

19. Koç İ, Eryurt MA (2017) The causal relationship between consanguineous marriages and infant mortality in Turkey. J Biosoc Sci 49(4):536-555

20. Adebowale AS (2017) Intra-demographic birth risk assessment scheme and infant mortality in Nigeria. Global Health Action 10(1):1366135

21. Arockiasamy A, Anburose A (2018) Infant mortality rate in India: mediating causes. Int J Health Care Qual Assur 31(7):784-795

22. Mathews T, MacDorman MF (2007) Infant mortality statistics from the 2004 period linked birth/infant death data set. Natl Vital Stat Rep 55(14):1-32

23. Finkelstein JZ, Duhau M, Speranza A, Marconi É, Escobar P (2016) Trend in infant mortality rate in Argentina within the framework of the Millennium Development Goals. Arch Argent Pediatr 114(3):216-222

24. Callaghan WM, MacDorman MF, Shapiro-Mendoza CK, Barfield WD (2017) Explaining the recent decrease in US infant mortality rate, 2007-2013. Am J Obstet Gynecol 216(1):73.e1-73.e8

25. Paul DA, Mackley A, Locke RG, Stefano JL, Kroelinger C (2009) State infant mortality: an ecologic study to determine modifiable risks and adjusted infant mortality rates. Matern Child Health J 13(3):343-348

26. Gonzalez RM, Gilleskie D (2017) Infant mortality rate as a measure of a country's health: a robust method to improve reliability and comparability. Demography 54(2):701-720

27. Khazaei S, Ayubi E, Nematollahi S, Khazaei S (2016) Variations of infant and under-five child mortality rates around the world, the role of human development index (HDI). Int J Pediatr 4(5):1671-1677

28. Liu L, Johnson HL, Cousens S, Perin J, Scott S, Lawn JE et al (2012) Global, regional, and national causes of child mortality: an updated systematic analysis for 2010 with time trends since 2000. Lancet 379(9832):2151-2161

29. Liu L, Oza S, Hogan D, Perin J, Rudan I, Lawn JE et al (2015) Global, regional, and national causes of child mortality in 2000-13, with projections to inform post-2015 priorities: an updated systematic analysis. Lancet 385(9966):430-440

30. Alkema L, Chou D, Hogan D, Zhang S, Moller A-B, Gemmill A et al (2016) Global, regional, and national levels and trends in maternal mortality between 1990 and 2015, with scenario-based projections to 2030: a systematic analysis by the UN Maternal Mortality Estimation Inter-Agency Group. Lancet 387(10017):462-474

31. Ebela I, Zile I, Mucina N, Ražuka-Ebela D, Rumba-Rozenfelde I (2015) Territorial differences in infant mortality in Latvia in the first decade of the third millennium. Cent Eur J Public Health 23:14-19
32. Ely DM, Driscoll AK, Matthews T (2017) Infant mortality rates in rural and urban areas in the United States, 2014: US Department of Health and Human Services, Centers for Disease Control and ...

33. Zylbersztejn A, Gilbert R, Hjern A, Wijlaars L, Hardelid P (2018) Child mortality in England compared with Sweden: a birth cohort study. Lancet 391(10134):2008-2018

34. Wang H, Abajobir AA, Abate KH, Abbafati C, Abbas KM, Abd-Allah F et al (2017) Global, regional, and national under-5 mortality, adult mortality, agespecific mortality, and life expectancy, 1970-2016: a systematic analysis for the Global Burden of Disease Study 2016. Lancet 390(10100):1084-1150

35. Brown Speights JS, Goldfarb SS, Wells BA, Beitsch L, Levine RS, Rust G (2017) State-level progress in reducing the Black-White infant mortality gap, United States, 1999-2013. Am J Pub Health 107(5):775-782

\section{Publisher's Note}

Springer Nature remains neutral with regard to jurisdictional claims in published maps and institutional affiliations.

\section{Submit your manuscript to a SpringerOpen ${ }^{\circ}$ journal and benefit from:}

- Convenient online submission

- Rigorous peer review

- Open access: articles freely available online

High visibility within the field

- Retaining the copyright to your article

Submit your next manuscript at $\boldsymbol{\nabla}$ springeropen.com 